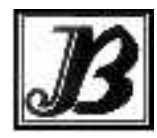

J. bio-sci. 21: 137-140, 2013

ISSN 1023-8654

http://www.banglajol.info/index.php/JBS/index

- Short Communication

\title{
THE REPRODUCTIVE CYCLE OF THE FRESH WATER FISH LABEO BATA (HAMILTON) (CYPRINIFORMES: CYPRINIDAE)
}

\author{
M A R Joadder \\ Dept. of Fisheries, University of Rajshahi, Faculty of Agriculture, Rajshahi- 6205, Bangladesh
}

\begin{abstract}
A total of 2200 specimens of Labeo bata (Ham.) were collected from rivers, beel and ponds of different local areas of Rajshahi region of Bangladesh during February 2007 to January 2009. For the study of reproductive cycle of $L$. bata, 1263 females (mature and immature) were used and the reproductive cycle was estimated. From this observation it was obvious that September to March was the breeding season but Peak in June to August for this species. Further observation reveals that no gravid female was found during the months from October to January of this study period. It was found that $L$. bata spawns once a year. The species is considered as major fresh water (Small indigenous species) fish in this country. So it is regarded as an excellent food for the people.

L. bata, because of its fresh water nature it received no attention in the scientific literature despite of its prominence among the fresh water fish and economic importance in the Indo-Pak-Bangladesh sub continent. It may also be mentioned here that no work has been done on reproductive cycle of this fish till now in this country although several workers have made significant contribution to the reproduction cycle in different fishes Alikundi (young canp-fry) 1952, Shafi and Quddus (Puntius stigma) 1974, Hossain et al. (Ompok Pabda ) 1992, Bhuiyan and Afroze (Oriochromis nilotica) 1996, Musa and Bhuiyan (Mystus bleekeri) 2007, Hossain et al. (Liza parsia ) 2009 .

Sexual developments involve the maturation of structural, physiological and behavioral machinery concerned with mating and reproduction and controlled by sex hormones (Charniaux 1954, Adiyodi and Adiyodi 1974). It is evident that like all other population of fishes, $L$. bata is on the decrease due to natural and other factors. A study of reproduction biology of $L$. bata is found to be essential in the sense that it may provide information and clues for a tactful and skilful culture and fishing of this species. The present study is aimed at providing a comprehensive account of the reproductive biology of $L$. bata.
\end{abstract}

Reproductive behavior in fishes is cyclic more or less regularly periodic (Lagler et al. 1967). The reproductive act in some fishes occurs only once in a very short life time, while in other fishes, it occurs in moderately long life span. Several other species spawn more than once in a year more or less continually. After spawning new group of oocytes is formed, which gradually mature to become ready for the next season.

Reproductive cycle of fishes depend upon several factors. Both light and temperature are important factors in controlling the maturation of gonads in fishes. Variation in the duration of light and temperature may influence the rate of gonadal development. According to Kinne (1971), most of the stages of reproduction often depend on certain condition of water movement. In rainy season particularly in June and July months after a heavy shower, the physico-chemical condition of water bodies abruptly changes and which in turn probably

* Corresponding address E-mail: raz2006_ru@yahoo.com 
stimulates spawning in most of the freshwater fishes (Jhingran 1977). Total length and ungutted weights of the fish were recorded to the nearest $1 \mathrm{~mm}$ and $1 \mathrm{~g}$ with the help of an electronic balance (Mfd. BY A \& D Co. Ltd. Korea) respectively. Two parts of the ovary from each fish were removed intact and placed in $10 \%$ formalin. Excess moisture was removed as far as possible by blotting the surface of the ovaries. The samples of the ovarian eggs were taken from the mid region of the ovary and the microscopical measurements of the diameter of the five ova for each specimen were taken at random and the average was calculated. After summing the month wise average diameter of ova was determined.

The total length, gonadal lengths were measured by using the meter scale or it necessary by using the fine point dividers. The following methods were applied to determine the reproductive cycle of $L$ bata accurately: Diameter of ova, Colour of gonad, Gonado-somatic index (G.S.I), Gondal length index (GLI) and Maximum egg bearing capacity.

a) Diameter of ova: Monthly average diameter of ovarian eggs of $L$. bata shows relationship with the seasonal cycle of the year. Month wise mean ova diameter were mentioned in the Table 1. Thus it was obvious that mature and ripe ova were commonly found in the ovary of mature female $L$. bata in between May and June, 2007 and June to August 2008. The highest reproductive activity was found in the species $L$. bata in July, 2007-2008 (Table 1).

b) Colour of Gonad: Spent and immature ovaries were whitish and transparent. With the increase of yolk deposition, the ovary become faint light yellow to yellow and opaque as well. The ripe and fully mature ovaries were yellow to deep yellow in colour. During the months of June to August all gravid females had yellow and light yellow ovaries which indicated the ripeness of gonad.

c) Gonado-Samatic Index (GSI): Out of 366 observation of GSI of female L. bata (mature and immature). The maximum and minimum values were observed 23.99 (July, 2008) and 2.37 (November, 2008) respectively. The mean GSI ranged from 23.13 to 1.05 (Table 1).

d) Gonadal Length Index (GLI): Out of 366 observation of GLI of female $L$ bata, it was noted that the length of the ovaries shows periodic changes. Higher values of GLI were found as 22.93 in July, 2008 and 22.72 in July, 2007 respectively. The mean GLI ranged from 21.04 to 8.36 (Table 1).

e) Maximum egg bearing capacity: Gavid female of $L$ bata in July, 2007 and July, 2008 bears more eggs than in other months of the year. Fecundity varied from 51354 (with a total length of $127.3 \mathrm{~mm}$ and a total weight of $20.00 \mathrm{~g}$ ) to 91568 (with a total length of $256.6 \mathrm{~mm}$ and a total weight of $156.70 \mathrm{~g}$ ).

In the present investigation the diameter of the ova and colour of the ovary had been studied. The mature and ripe ova were also found towards the periphery and the immature and maturing ova were in the center. It can be concluded from the above findings that the breeding season of $L$. bata starts from September and Continue till March. June to August is the peak breeding season of the $L$. bata. Thus, it is a monospawner and highly fecund fish for its size. 


\section{Space for Table 1}




\section{Acknowledgment}

The author remains grateful to Dr Md Delwer Hossain, Associate Professor and Chairman, Department of Fisheries, University of Rajshahi, Rajshahi, Bangladesh for his kind cooperation during this work.

\section{References}

Alikundi KH 1952. On the food of young canp-fry. J Zool Soc India 4(1), 77-84.

Adiyodi KG, Adiyodi RG. 1974. Comparative physiology of reproduction of Arthropods: Comparative physiology and biochemistry. Acad. Press New York and London 5, 37-107.

Bhuiyan AS, Afroze R. 1996 b. The fecundity and sex-ratio of Oriochromis nilotica (L) (Perciformes :Cichlidae ) Uni J Zool Rajshahi Univ Vol. 14\& 15, 29-32.

Bhuiyan AL. 1964. Fishes of Dacca. The Asiatic society of Pakistan Dhaka. pp.148.

Charniaux CH. 1854. Decouverta chazue crustacean amphipod (Orchestra gammarella) dune gland endocrine responsible dela differentiation des characters sexual primaries et secondaries males C.R.A. Cad. Sci. Paris. 239, 708-782.

Hossain MA, Taleb A, Rahman MH. 1992. Reproduction and fecundity of Ompok Pabda (Ham.) Bangladesh J Sci Res 10(1), 49-52.

Hossain MD, Joadder AR, Khanom DA, Kamruzzaman SW. 2009. The reproductive cycle of the brakish water fish, Liza parsia (Hamilton) (Mugiliformes : Mugilidae). J Sci Foundation 7(1), 95-97 .

Jhingran VG .1977. Fish and fisheries of India, 2nd Ed. Hind. Pub. Corp. India, 954 pp.

Kinne O .1971. Marine ecology. Wiley Inter. Science (Division Johan Wiley Sons Ltd.) New York. 1244 pp..

Lagler KF, Bardach JE, Miller AR. 1967. Ichthyology.Ibid. Sydney. p. 545

Musa ASM, Bhuiyan AS 2007.Fecundity of Mystus bleekeri (Day, 1877) from the river Padma Rajshahi city. Turkish Journal of Fisheries and Aquatic Sciences 7, 161-162.

Nash CE, Shehadesh ZH. 1980 . Riview of breeding and propagation techniques for gray mullets, Mugil cephalus L. ICLARM Studies and review.3 pp. 75.

Shafi M, Quddus MMA. 1974. The fecundity of the common Punti, Puntius stigma (Cyprinidae: Cypriniformes ). Bangladesh J Zool 2(2), 133-145. 